\title{
Perception and Preference of Media in Debre Tabor City Administration: Assessing Media Perception and Preference of Choosing the Media of Debre Tabor Community
}

\author{
Destaw Bayable Yemer \\ Researcher and Lecturer, Guna Tana Integrated Field research and Development Center, Debre Tabor University, \\ Debre Tabor, Ethiopia \\ Dessalegn Yeshambel Wassie \\ Lecturer, Debre Markos University, Department of Journalism and Communication, Debre Markos, Ethiopia
}

\begin{abstract}
This study is on media perceptions and preferences of choosing the media in Debre Tabor Community in 2018. Media in Debre Tabor is very important and crucial for social change. Due to this, it focused on the assessment of audiences' media perceptions and preferences. So as to assess the community perceptions and preferences, mixed research design was employed. The data was gathered through survey questionnaires which consisted quantitative and qualitative questions and focus group discussion. For this study, 827 questionnaires were distributed to Debre Tabor Community. The results indicate that Debre Tabor Community had a good perception for the media and they were accessed different media for information, education and entertainment. The study testified that media used for them for entertainment, getting basic knowledge and information and they used as a means of correlation. They dominantly used TV, internet and radio as sources of information and entertainment. They believed that media transmitted the message for the sake of public and government benefits, but the agendas are government agendas. Timeliness, credibility, and impartiality are their criteria to consume media messages. The program content, credibility, preferably, freedom, media type and ownership are some factors that influenced their media choice.
\end{abstract}

Keywords: Preference, Perception, Media, Debre Tabor Community

DOI: $10.7176 / \mathrm{NMMC} / 86-01$

Publication date: December $31^{\text {st }} 2019$

\section{Introduction}

\section{Background of the study}

We are living in a $21^{\text {st }}$ century in which different types of media are doing their utmost attempt to attract the attention of the audience [1]. Globally, audiences have different awareness pertinent to different media outlets and its multi-dimensional roles [2]. In addition to this, media contents are addressed to a large number and heterogeneous audiences'. Regardless of this, different scholars are stated the functions of media. Media play many different and maybe incompatible roles. Dominick (2009)[3] also stated that mass media have surmounting the role of surveillance, interpretation, linkage, transmutation of values and entertainment function for the society. According to Elihu Katz, Jay Blumler, and Michael Gurevitch (1974) [4], mass media have the role of cognition, diversion, social utility, and withdrawal in the decade we are living in.

Besides to these, Wright (1974) [5], realizing that how conceptualization of media functions was misinterpreted, later he wrote:

Our working quartet of communications-surveillance, correlation, cultural transmission, and entertainment-was intended to refer to common kinds of activities that might or might not be carried out as mass communications or as private, personal communications. These activities were not synonymous for functions, which ...refer to the consequences of routinely carrying out such communication activities through the institutionalized processes of mass communications.

Mass media are effective means of communication, spreading information, advertising, marketing, and in general, expressing and sharing views, opinions, and ideas in different contexts (Mockba, 2012). People are exposed to information about the world by the news media. While this information shapes one's opinions about the world, attitudes toward the media themselves are also developed in the course of news consumption, or targeted to the way specific topics are covered by news media. Three important types of attitudes toward media have been identified by research; they relate to trust in media (Kohring \& Matthes, 2007), perceptions as to whether media favor or are hostile toward specific topics or groups and beliefs about how powerful media are and how they affect the self, other individuals, and society.

The classic articulation of this framework is the one offered by Elihu Katz [et al] (1974). They described five elements, or basic assumptions, of the uses-and gratifications model: (1) The audience is active and its media use is goal-oriented, (2) The initiative in linking need gratification to a specific media choice rests with 
the audience member, (3) The media compete with other sources of need satisfaction, (4) People are aware enough of their own media use, interests, and motives to be able to provide researchers with an accurate picture of that use and (5) Value judgments regarding the audience's linking its needs to specific media or content should be suspended. Media often act as the bridge between our personal/private lives and the public world.

Social perception in the way how we mean that how we make sense of social world, this is related to phenomenon that how we make impressions of and make inferences about other people. Severin (2001) further suggests that different people react to same message in a very different way, and this is all related to the process of decoding; that how people process specific information. But sometimes exposure to selective content on media plays a very significant role in making up perceptions towards certain issue. According to Turner and West (2007), Selective exposure "is a method for reducing dissonance by seeking information that is consonant with current beliefs and actions".

Similarly, Chan (2007), described the role of media in guiding public opinion, he mentioned that three guidance of public opinion is more indirect, flexible and subtle way of dealing with public opinion. He further elaborated that media's role in guiding public opinion is somewhat related to the concept of propaganda by shifting the focus on "what people think" to "what people think about". This is the main hub of media, to give issues to public for what they think and act accordingly of the perceptions they have and in many cases what media give them direction to perceive and act on. Societies are affected by the function of media for providing information, but this could vary from individual to individual. It can be related with the need for orientation which is a cognitive action of an individual about certain topic or issue.

Media could be strong enough through its surveillance function, and it can have a very strong impact through contemporary news media. Media's functions also include socialization function which is to transfer specific culture among people of the society. A journalistic function of media is to provide information on each and every aspect of all issues of the globe at doorstep of the target audience. Due to this fact, media can influence the public opinion and perceptions very easily, because in this era of technological revolution generally public rely on media for immediate and actual information of the surroundings, therefore pubic can easily be influenced from the content of media and it becomes very easy to mold and influence the general public opinion in a dimension and direction where media wants to. In present era media can be used as tool by which one could control the minds of people or could produce the climate of harmony. But sometimes media can produce conflict between different societal groups and the result would be in the shape of instability within the society or vice versa. This can relate to media construction of social reality, that how media is successful in constructing some important aspects of reality out of nowhere, or sometimes from the facts and happenings that go unnoticed in society. Again this is very important role of media to construct certain aspects on one issue or more than one issue and then to present in front of public to make certain perceptions accordingly whatever media constructed.

There are different roles of media including; providing education, entertainment, information in addition to the role of gate keeping which is to keep a check and balance that which information is passing by and which is not. Hence, this study examines the media perceptions and preferences of Debre Tabor community, especially in this zone there is not media plurality. Due to this, it assesses the media perceptions and preferences of the community.

\section{Statement of the problem}

Mass media has certain tasks in social life. It does an important public service in form of establishing the rules and policies of democracy, because it is the fourth state of the country. It gives opportunities to social groups that have different ideologies, philosophy and beliefs. Despite being a relatively recent development the mass media plays a crucial role in forming and reflecting public opinion. It communicates the world to individuals, and it reproduces modern society's self-image. The media are described as performing three functions or roles of information, education and entertainment. It is not in ideal form it must do as active involvements. Media entice people to change. However, media can only do so much when it comes to influencing people in making major attitudinal change with respected to perception and preference.

According to South Gonder Zone profile, the zone has 10 districts/wordas and 5 City administrations. Most of the districts are mountainous. Due to this and other problems the community lives in disparate area. South Gonder is far-off Zone in national media converge: it is $666 \mathrm{~km}$ far from the capital Addis Abeba. Hence, in Ethiopia there are different media outlets that are owned by government and private sector. It includes satellite $\mathrm{TV}$ and radios. However, the media institutions didn't know the peoples' media perceptions and media preferences. They only owned media license and broadcasting their programs in the capital city. It incites the researchers to know the community media perceptions and preferences. In addition to this, there is no media plurality in South Gonder Zone: only government media coverage have been found and consumed here in Debre Tabor. Inaccessibility of media hinders the Zone development and image: depend on the result the government, public or any interested person will establish a preferable media. There is no accessible and free media forum for 
this community at zonal level. So, it has been working for the sack of media accesses, participation and dialogue. Therefore, the main intention of this paper is to assess media perception and preference with regard to accessibility in the case of Debre Tabor city administration and its community in general.

\section{Research Questions}

Having this in mind, this research draws the following basic research questions and hypostasis.

Q1. What the community thinks about media with respect to different media outlets in a country?

Q2. Which media are preferable for the community?

Q3. What media contents do the community most regularly consume?

Q4. What are the most determinant factors that affect the community's media perceptions and preference in the town?

\section{Objectives of the study}

\subsection{General Objective}

The main objective of this research is to examine media perception and preference of Debre Tabor community pertinent to their level of understanding.

\subsection{Specific Objectives}

Besides to the general objective, this study specifically tries to:

- identify the preferences of the community in print and electronic media: investigate how the community allocate their time across traditional and new media activities:

- examine how media choice vary among the community with in the same town:

- $\quad$ assess the awareness of the community in relation to media roles

- identify the types of media outlet that they are in use

- Explore determinant factors that affect their perception and preferences

\section{Significances of the study}

This research paper has much significance for the community of Debre Tabor and stockholders of the media organization in the state. Firstly, it helps the community to open their preferable media and empower the community. Secondly, the media institutions can use it to prepare their own program schedule. In addition, it is a community service for the institution to assess the demand and open preferable media to the community. Furthermore, it helps the regional and state government to address their public policy through appropriate media. Moreover, the paper will take part in filling some knowledge gaps in relation to public's media perceptions and preferences and the findings may help other researchers and media professionals to carry out further research within this field.

\section{Methodology of the study}

\subsection{Study design}

This study aims to assess the perception and preference of the media in Debre Tabor community. It uses both quantitative and qualitative research method. Mean that mixed research approach is employed because it has many significance of the study. Mixed methods research takes advantage of using multiple ways to explore a research problem. The data gathered through a survey questionnaire and focus group discussion (FGD). The selection and construction of a measurement scale requires the consideration of several factors that influence the reliability, validity, and practicality of the scale (Cooper \& Schindler, 2006). The respondents is enquired for offering their responses, experiences in media perception and preferences.

\subsection{Data Collection and Measurement}

This study assesses the community's opinions about the media perceptions and preferences for entertainment, communication and information to improve their life and live performance and socialization with regard to perception and preference, this study will employ use and gratification theory as an underlying theoretical framework or model the underlying theories will employ; use and gratification. The questionnaires will consist of open-ended and close-ended survey questions. The questionnaires will consist of around 24 questions pertaining to background information, the intention to the media perception and preference their daily media consumption. The questions will also aim to measure the community's' perceptions and preference of media use in surveillance and its influence on their live performance. As well as the most determinant factors foe their level of perception and preference of media.

\subsection{Sampling size and techniques}

The study is used a purposive sampling method to ensure a good representation of the target group that is 
Debre Tabor community as users of the media. Debre Tabor was established as one of the 12 city administrations in the region in the year of 2003. It has four urban and four rural kebeles (urban; kebele 1-4 and rural; Debre Tabor Eyesus, Hiruy Abaregay, Woyebla selamko, Tsegur adiko). The researchers selected only 827 people as sample respondents in four urban kebeles and two rural kebeles. In the six kebeles, 827 people will select as a respondent for questioners and 12 FGD by using purposive sampling techniques to obtain information about their perceptions and the preferences of media in community.

\subsection{Data Collection}

Data will be collected by using a survey questionnaire. The questionnaire is in paper versions. The questionnaires are addressed to the respondents via using the respondent's worda/kebele administration government communication office. The respondents are targeted based on media-closeness because they ordinarily encompass diverse populations consisting of different majors in sex, age, education etc. There is also more likelihood of obtaining a sample that fell within the target audience. The questionnaire (Amharic version) is pre-tested with selected 37 respondents and adequate adjustments are made to clarify some questions that had earlier proved ambiguous.

\subsection{Data gathering Instruments}

\subsubsection{Questionnaires}

In the city administration, there are eight kebeles (kebele1-4 in the town), and four in the rural, so the researchers are used different mechanism to handle and collect the data. The questionnaire comprises 24 questions that elicit both quantitative and qualitative data. This is a deliberate effort aim at collecting rich data, especially with the qualitative questions that allow people to articulate their opinions and provide richer responses as opposed to pre-packaged responses. Follow-up questions also provide opportunity for qualitative answers. Respondents are asked to check off the uses pertinent to them. Demographic information on age, gender, education, religion and district also obtained besides to media perception and preference questions.

\subsubsection{Focus Group Discussion (FGD)}

This research also used FGD to gather qualitative data. Researchers agreed that in qualitative research the most common research method is focus group discussions. As Powell [et al] (1996), defines that a focus group as "a group of individuals selected and assembled by researchers to discuss and comment on, from personal experience, the topic which is the subject of the research. The main purpose of focus group interviews is to draw upon respondents' attitudes, feelings, beliefs, experiences and reactions, in a way which would not be feasible using other methods (Kitzinger, 1995). So, as per these facts, it is imperative to use focus group discussion to study the community perceptions and preferences with media as it helps to get the community feelings, attitude and reactions. In one FGD 8-12 people were included and the study was collect the data within 12 FGD participants.

\section{Data Analysis}

The questionnaire is entered to SPSS 20 software. The software was provide a compilation of the raw data as well as a summary of responses arrange by questions. The data download onto an Excel spreadsheet and frequency tables, charts and graphs are drawn from the summaries. Data from the open-ended questions and focus group discussion coded to generate categories, and later themes. For the sack of respondents' privacy, we put in form of focus group discussion participant (FGDP) 1, 2, $3 \ldots 12$. The themes then entered in an Excel spreadsheet from which pivot tables are generated for frequencies of responses. The questions which had similarities in different cases are merged or it makes in crosstabulation form.

\section{Scope of the Study}

This study is delimited to both content and geographical size. Geographically, the study is limited to Debre Tabor City Administration in 2018/19 and content wise it is limited to perception and preference of media.

\section{Data Analysis and Interpretation}

Table 1: Respondents Gender and Residence Biographic Data

Gender of the respondents * Residence kebeles of the respondents Crosstabulation

\begin{tabular}{|ll|l|l|l|l|l|l|l|}
\hline & & \multicolumn{6}{l|}{ Residence kebeles of the respondents } & \multirow{2}{*}{ Total } \\
\cline { 3 - 8 } & & 1 & 2 & 3 & 4 & 5 & 6 & \\
\hline \multirow{2}{*}{ Gender of the respondents } & Male & 108 & 95 & 68 & 90 & 52 & 48 & $\mathbf{4 6 1}$ \\
& Female & 104 & 83 & 67 & 79 & 25 & 8 & $\mathbf{3 6 6}$ \\
& & $\mathbf{2 1 2}$ & $\mathbf{1 7 8}$ & $\mathbf{1 3 5}$ & $\mathbf{1 6 9}$ & $\mathbf{7 7}$ & $\mathbf{5 6}$ & $\mathbf{8 2 7}$ \\
\hline
\end{tabular}

As it has been stated in table one, $827(461$ males and 366 females $)$ from six kebeles $\left(\mathrm{K}_{1}-212, \mathrm{~K}_{2}-178, \mathrm{~K}_{3}\right.$ - 
$135, \mathrm{~K}_{4}-169, \mathrm{~K}_{5}-77$ and $\left.\mathrm{K}_{6}-56\right)$ respondents were involved in this study. They were selected based on purposive sampling method.

Table 2: Ages and Educational levels of the respondents Age of the respondents * Educational levels of the respondents Crosstabulation

\begin{tabular}{|c|c|c|c|c|c|c|c|c|c|c|}
\hline & \multicolumn{8}{|c|}{ Educational levels of the respondents } & \multirow[t]{2}{*}{ Total } \\
\hline & & Elementary & Secondary & Preparatory & College & University & Degree & $\begin{array}{l}2^{\text {nd }} \\
\text { Degree }\end{array}$ & \begin{tabular}{|l|}
$\mathrm{PhD} /$ \\
Professor
\end{tabular} & \\
\hline \multirow{6}{*}{$\begin{array}{l}\text { Age of the } \\
\text { respondents }\end{array}$} & $10-15$ & 8 & 2 & 2 & 0 & 0 & 0 & 0 & 0 & 12 \\
\hline & $16-21$ & 38 & 52 & 115 & 50 & 46 & 15 & 2 & 0 & 318 \\
\hline & $22-30$ & 11 & 18 & 17 & 53 & 78 & 72 & 12 & 0 & 261 \\
\hline & $31-40$ & 11 & 5 & 9 & 21 & 10 & 77 & 8 & 2 & 143 \\
\hline & 41 and & 9 & 0 & 2 & 41 & 3 & 38 & 0 & 0 & 93 \\
\hline & & 77 & 77 & 145 & 165 & 137 & 202 & 22 & 2 & 827 \\
\hline
\end{tabular}

As shown in the above table, Participants were in different age ranges; 12 participants are in ages of 10-15, 318 participants are in ages of 16-21, 261 participants are in ages of 22-30, 143 participants are in ages of 31-40 and 93 participants are in the ages of 41 and above. Therefore, participants, which were involved in this study, are in different age ranges. In addition to this, respondents have different educational level (i.e. 77 elementary, 77 secondary, 145 preparatory, 165 college, 137 university students, 202 degree holders, 22 second degree holders and 2 third degree holders). The respondents' age and educational level variety had a good contribution for the effectiveness of this study.

Table 3: Religious of the Respondents

\section{Religious of the Respondents}

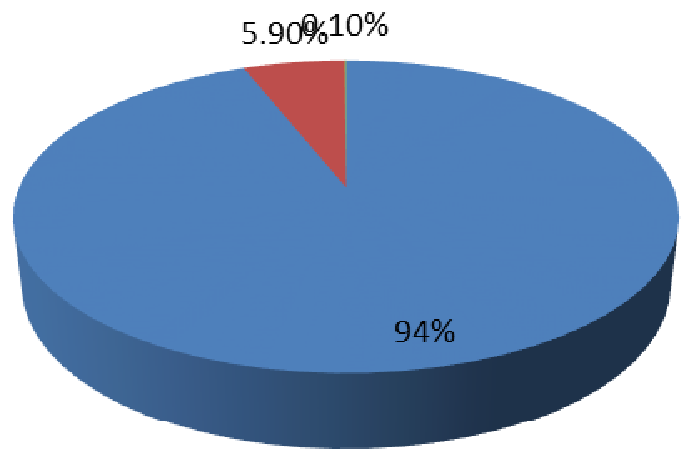

Orthodox

Muslim

Protestant

Line with the respondents' ages, in the biographic data of the respondents, the study tried to identify the religions of the respondents. Within the total sampled population $94 \%$ of the respondents are followers of Orthodox religion, 5.9\% of them are Muslim religious followers and the rests are Protestant religious followers. So, the religions of the respondents have its own impact on the perception and preferences of the media. There are different channels that disseminated their program in satellite form.

"We select the channels depend our interests; we are eager to hear and see religious programs in TV. Besides to this, the family member characteristics determine our media choice." (FGDP 2 and 5)

The discussant stated that their religion has an impact on the media preferences. 
Table 4: Respondents Media Awareness and Images for the Media

Do you know types of media? * Do you have a good image for media? Crosstabulation

\begin{tabular}{|lc|l|l|l|}
\hline \multicolumn{2}{|c|}{} & \multicolumn{2}{|l|}{ Do you have a good image for media? } & \multirow{2}{*}{ Total } \\
\cline { 3 - 4 } & Yes, I have & No, I haven't & \\
\hline \multirow{2}{*}{ Do you know types of media? } & Yes & 705 & 60 & $\mathbf{7 6 5}$ \\
Total & No & 39 & 23 & $\mathbf{6 2}$ \\
\hline
\end{tabular}

As the data stated in table 4, 765 respondents surely know the types of media and they (744) had a good image for media. Some of them also they hadn't a clear knowhow about media and they hadn't a good perceptions for media. In addition to this, they were asked openly about their perceptions of media, though they had good perceptions to the media and they use it regularly to seek information, what is going on around them. However that their perceptions and knowledge of the media were varied depend on their educational status, age level and gender. Aged, educated and males had a relatively good image and knowledge for the media.

"We know and use the accessible media for seeking information and entertainment programs but we also have a good image for the preferable media especially Amhara TV, ETV and ESAT." (FGDP 5)

They testify that media are very important to update their knowledge, to develop their skill and attitude and to empower and entertain. As they sated, the community perception determined based on the media credibility and accuracy of information that presented by the media.

\section{Table 5: Types of Media that used regularly and the Media which used as real Sources of Information}

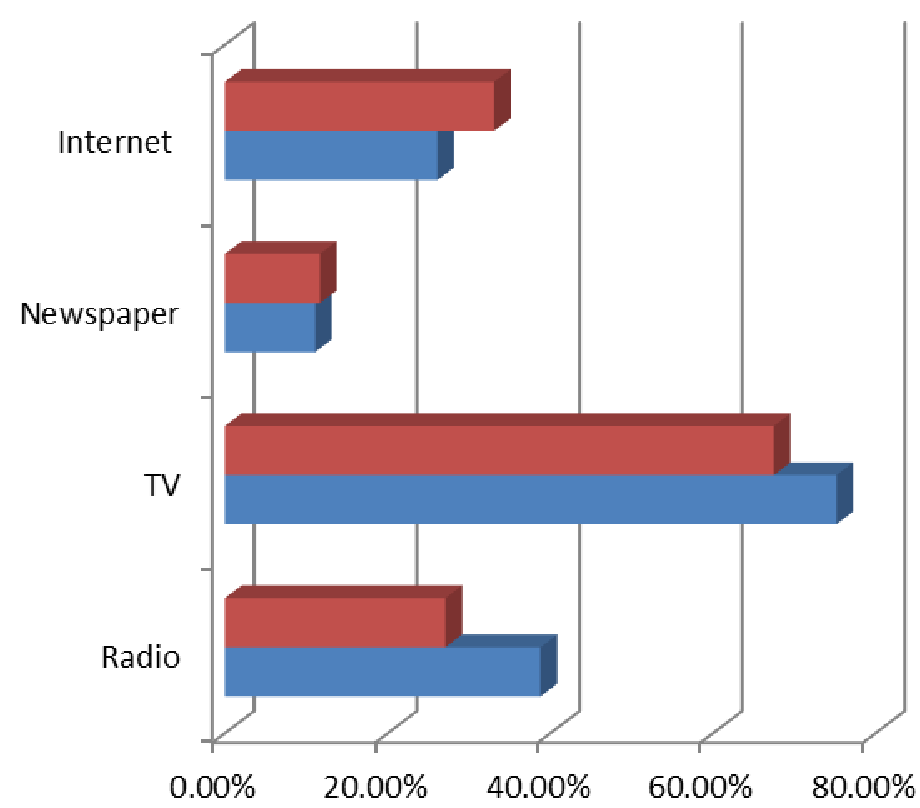

Respondents real sources of information

- Types of media which used regularly

As shown graph 5, most of the respondents were used TV (75.2\%), radio (38.8\%), internet (26.1\%) and newspaper $(11.1 \%)$. Except few, most of the respondents were preferable more than one media. The respondents have variety media choice especially TV and Radio. As they stated most of the respondents have the medium as their property and the medium have their own power to impress them. These two media are potential and preferable to serve both literate and illiterate people. Internet and newspaper takes the second position.

“...the accessibility of newspaper and the coverage of internet is low. We only get 'Bekur' newspaper in one book shop. The strength of the internet is weak and slow." (FGDP 4, 7 and 10)

Even if there is low coverage and less access of internet coverage in this zone, some of them they are in favor of internet to use for social media. Youth people are highly dependent with social media. This new age media highly attract the net-generation. The traditional print media is the least consumed media in Debre Tabor community. There had different reasons why they were not use newspaper; low access of new media, old fashioned media, less attractiveness, outdated information and etc. were some of them as they mentioned.

In line with the above, the majority $(67.5 \%)$ of the respondents were used TV as a real sources of information. Internet $(33.1 \%)$, radio $(27.1 \%)$ and newspaper $(11.7 \%)$ were also used as a source of information for the community. TV is advanced channel to receive and understand information easily with in the context. This is the reason why most of the people selected TV as a source of information. In addition, as some study stated the new generation is dependent to web to seek information. So, the new media and traditional media have 
their own preferably based on age difference.

On the other hand, when we see the real ground of the area, there is no any newspaper access; there is only one small shop that distribute local newspaper. Besides to this, the geographical topography of the areas is difficult for radio frequency coverage. Only shortwave frequencies are capable to cover the area. The national and regional media transmitter antennas are in distance.

So, the community preferences are determine based on the access and infrastructures of the media. Satellite TV is the beset to seek info here in Debre Tabor community.

Table 6: What is/are the function(s) of media to you?

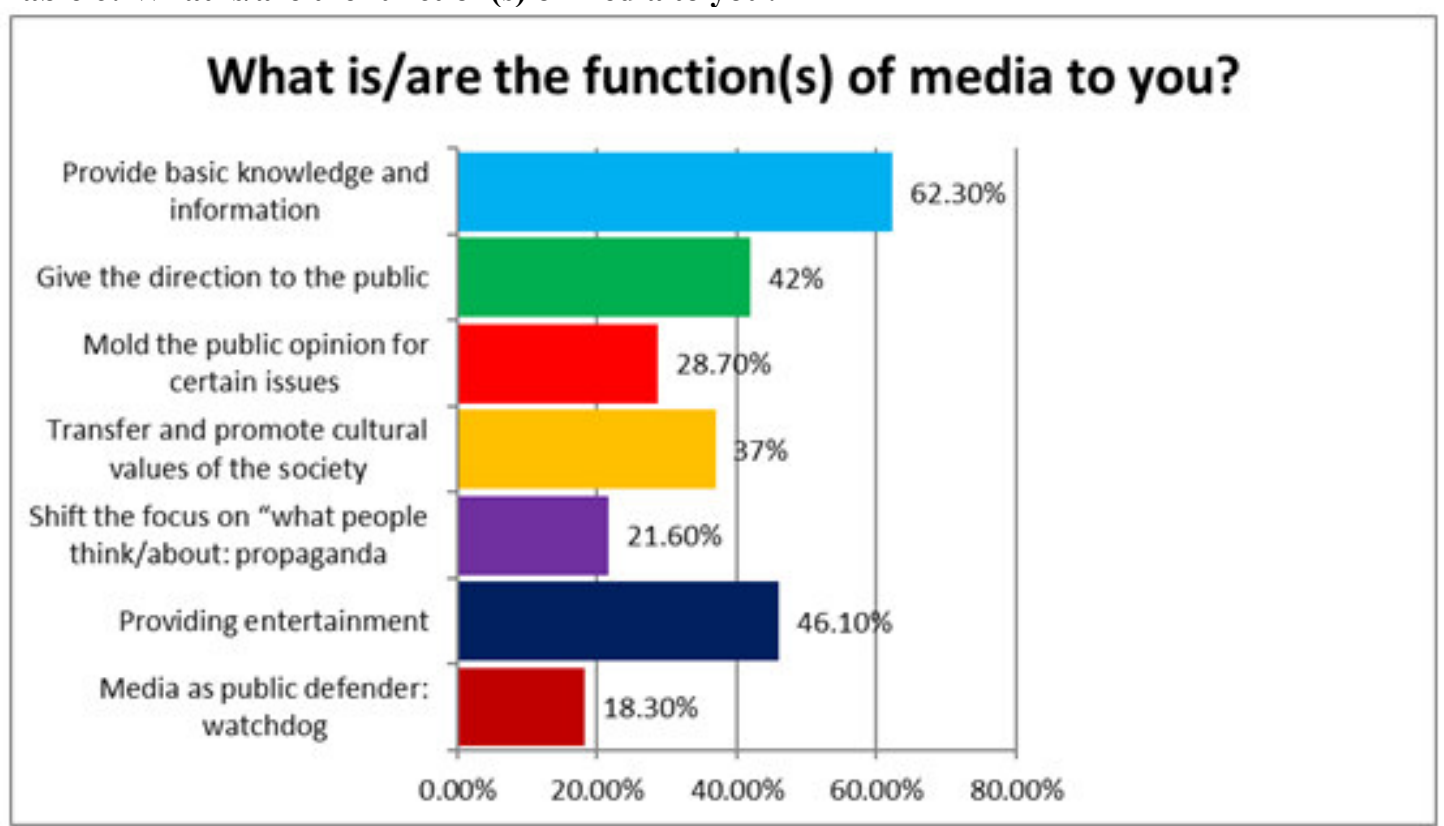

As shown table 6 , most of the respondents believe that media have different functions. These are provide basic knowledge and information (62.3\%), providing entertainments $(46.1 \%)$, giving the direction to the public $(42 \%)$, transferring and promoting cultural values of the community $(37 \%)$, molding the public opinion for certain issues $(28.7 \%)$, shifting the focus on "what people think/about": propaganda $(21.6 \%)$, and playing watchdog roles $(18.3 \%)$.

Societies are affected by the functions of media for providing information, but this could be varying from individual to individual. The functions of media can be related with the needs for orientation. Media have surveillance function, socialization function, informational function, watchdog function and entertainment function.

"As others community, we use media to know what is going around us, to read or listen government announcements, mobilization and entertainment. Most of the time, we use it to entertain us." (FGDP 1, 4 and 11)

The discussants said that media helped them to validate the government activities and implementations. In addition they used to develop their cultural values, norms and traditions and transfer for the next generation. Due to this fact, media can influence the public opinion and perceptions different extent.

As stated in the discussion, the respondents believe that media have many functions. The media in the community are providing basic knowledge and information. It facilitated to upgrades their knowledge, attitude and skills in different forms. Besides to this, the media presents entertainments programs for them. 
Table 7: For what purpose do you use media?

\section{For what purpose do you use media?}

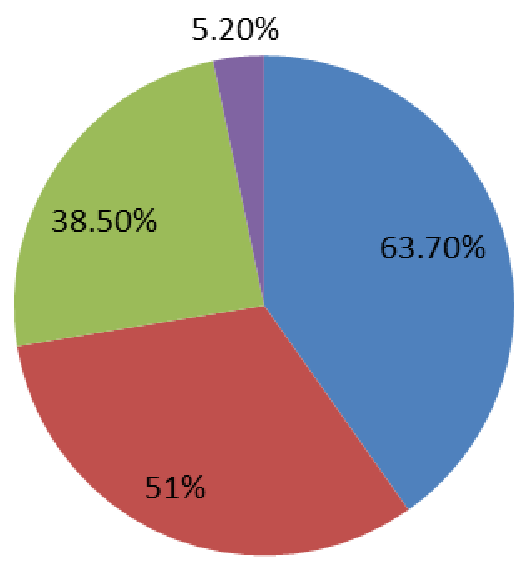

To inform

To educate

To entertain

To persuade

Besides to the respondents' beliefs, $63 \%$ of the respondents were use media to get information about any issues. $51 \%$ of them were used to educate about any aspects. Whereas, $38.5 \%$ of the respondents were certain that they use media to entertain themselves. The rest (5.2\%) argued that they use it for the purpose of persuading.

Societies are consumed media messages for different purposes. This can relate the media construction of social reality. Besides of the media gatekeeping roles, it is providing education, entertainment and information.

"... we are in the developing county; there is not job opportunity. Then we spent our time by consuming media products for the sack of entertain, inform and educate." (FGDP8 and 12)

Here, in Debre Tabor have not any manufacturing factory. Few government organizations and some private small business are the only sector that the community engaged. The community receive, understand, interpret, and analysis the information that consumed with different media. The process is successful in providing an impact regarding the community's media perception.

Recognizing all of these, the media purpose has its own contribution in the choices and uses of media.

Table 8: For whom benefit media in a country are transmitted their message?

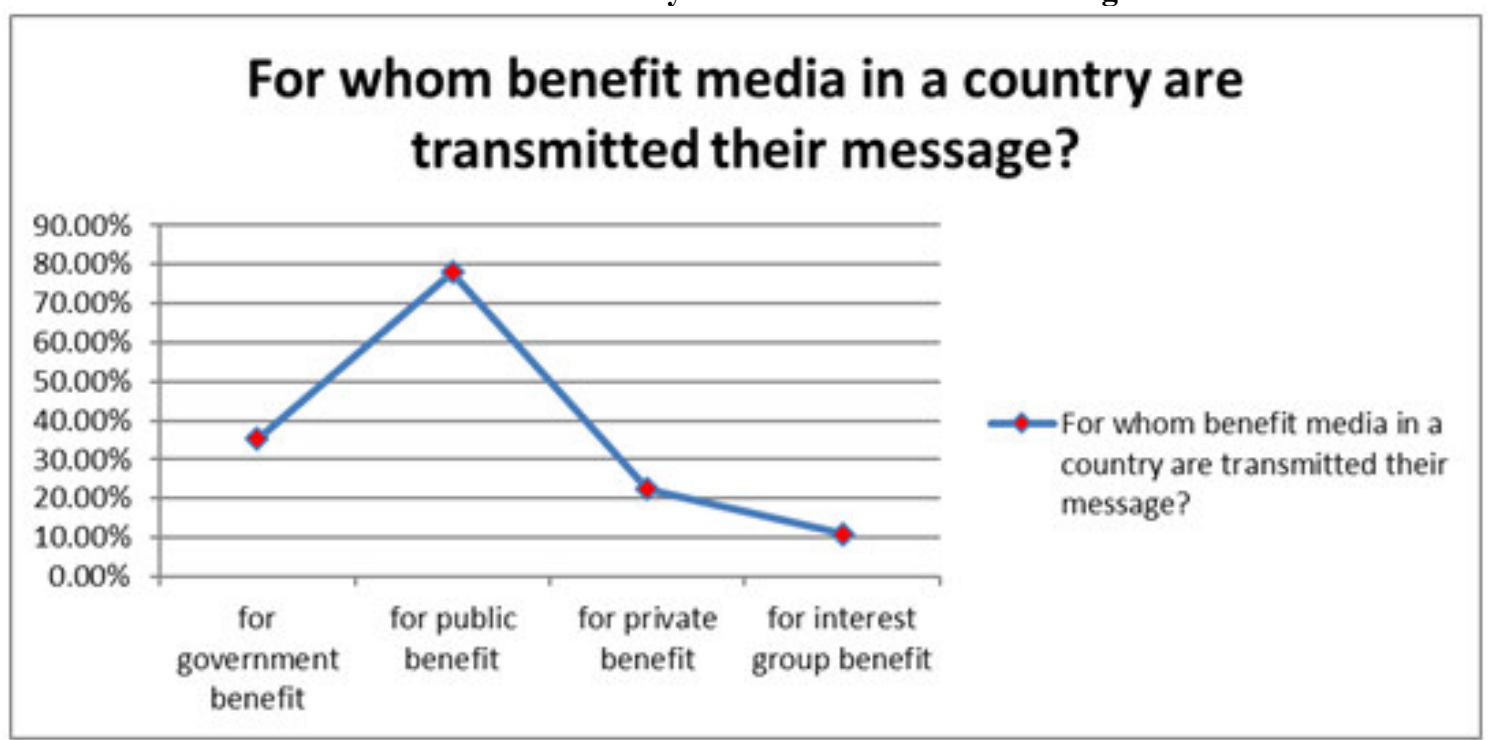

In line of the above table, the respondents tries to state to whom benefits media in a country are transmitted their message, though $78 \%$ of the respondents believes that media are transmitted their message for public interest, $35.2 \%$ for government benefit, $22.4 \%$ for private benefit and the rest $10.9 \%$ assured for the interest group benefit.

Media have to guiding public opinion; guidance of public opinion is more indirect, flexible, and subtle way of dealing with public opinion (Chan, 2007). Here, in Ethiopian context major national and regional media are hold by the government. These are the only media have a coverage in Debre Tabor town. Due to this, the media 
are done for public and government benefits. There are also limited satellite TVs and online Media which are owned privately. These media also are done for private and interest group benefits.

"We are the part of the government. Media are transmitted messages for both benefits. However, the government policies and propagandas takes the high coverage in the media." (FGDP 3, 6 and 9) Thus, in consideration of the above, the media runs their functions for the purpose of the public. Government and private media governed by Ethiopian Broadcast Authority, so they have to take any directions in the state level.

All the information stated above help us to decide the perceptions of the community in form of media functions, purposes and types. Though the respondents have good attitudes for media and they were identified the purpose of media for information and education which changes and upgrade their attitude and shapes what they think.

According to the finding, Debre Tabor community has good perceptions for the media, but they haven't good access to use it. To fulfill such a role, beneficiaries contribute in inaugurations of media institution.

Table 9: Times, the Respondents Spent on TV Outlet

3.1. How much time do you spend on the following media on a daily basis?

\begin{tabular}{|l|l|l|l|l|l|l|l|l|l|l|l|}
\hline \multirow{2}{*}{ TV } & None & \multicolumn{2}{l|}{ Less than 1 hr. } & 1-2hrs. & \multicolumn{3}{l|}{ 3-4 hrs. } & \multicolumn{2}{l|}{ and above hrs. } \\
\cline { 2 - 13 } & Frequency & $\%$ & Frequency & \% & Frequency & \% & Frequency & $\%$ & Frequency & $\%$ \\
\hline EBC $_{1}$ & 320 & 38.7 & 311 & 37.6 & 138 & 16.7 & 41 & 5.0 & 17 & 2.1 \\
\hline EBC $_{3}$ & 312 & 37.7 & 294 & 35.6 & 176 & 21.3 & 33 & 4.0 & 12 & 1.5 \\
\hline Amhara TV & 144 & 17.4 & 318 & 38.5 & 293 & 35.4 & 49 & 5.9 & 23 & 2.8 \\
\hline Fana TV & 322 & 38.9 & 283 & 34.2 & 143 & 17.3 & 55 & 6.7 & 24 & 2.9 \\
\hline Addis TV & 435 & 52.6 & 252 & 30.5 & 105 & 12.7 & 24 & 2.9 & 11 & 1.3 \\
\hline South TV & 607 & 73.4 & 160 & 19.3 & 33 & 4.0 & 25 & 3.0 & 2 & 0.2 \\
\hline Oromia TV & 656 & 79.3 & 107 & 12.9 & 36 & 4.4 & 24 & 2.9 & 4 & 0.5 \\
\hline Tigray TV & 637 & 77.0 & 118 & 14.3 & 50 & 6.0 & 18 & 2.2 & 4 & & 0.5 \\
\hline Walta TV & 365 & 44.1 & 240 & 29.0 & 134 & 16.2 & 68 & 8.2 & 20 & 2.4 \\
\hline EBS & 253 & 30.6 & 205 & 24.8 & 202 & 24.4 & 108 & 13.1 & 59 & 7.1 \\
\hline ENN & 327 & 39.5 & 246 & 29.7 & 150 & 18.1 & 85 & 10.3 & 19 & 2.3 \\
\hline Kana TV & 297 & 35.9 & 193 & 23.3 & 196 & 23.7 & 82 & 9.9 & 59 & 7.1 \\
\hline JTV & 421 & 50.9 & 223 & 27.0 & 122 & 14.8 & 34 & 4.1 & 27 & 3.3 \\
\hline ESAT TV & 509 & 61.5 & 186 & 22.5 & 80 & 9.7 & 24 & 2.9 & 28 & 3.4 \\
\hline Nahoo TV & 547 & 66.1 & 162 & 19.6 & 74 & 8.9 & 33 & 4.0 & 11 & 1.3 \\
\hline MoE & 650 & 78.6 & 120 & 14.5 & 29 & 3.5 & 18 & 2.2 & 10 & 1.2 \\
\hline
\end{tabular}

As stated in table 9, the majority of the respondents consumed different programs from the media outlets.

Most of the respondents didn't spent any time on TVs (i.e. ; ETV1-38.1\%, ETV3-37.7\%, Amhara TV-17.7\%, Fana TV-38.9\%, Addis TV-52.6\%, South TV-73.4\%, Oromia TV-79.3\%, TgTV-77\%, Walta TV-44.1\%, EBS$30.6 \%$, ENN-39.5\%, KanaTv-39.9\%, JTV-50.9\%, ESAT-61.5\%, Nahoo TV-66.1\% and MoE-78.6\%.

On the other hand, some of the respondents were spend less than one hour and consumed the information from different TVs; ETV1-37.6\%, ETV3-35.6\%, Amhara TV-38.5\%, Fana TV-34.2\%, Addis TV-30.5\%, South TV-19.3\%, Oromia TV-12.9\%, TgTV-14.3\%, Walta TV-29.0\%, EBS-24.8\%, ENN-29.7\%, KanaTV-23.3\%, JTV-27.0\%, ESAT-22.5\%, Nahoo TV-19.6\% and MoE-14.5\%. In addition to this, the others spent 1-2 hours.

As stated above, ETV1, ETV3, Amhara TV, Fana TV, Walta TV, EBS, ENN, Kana TV, and JTV relatively consumed by the respondents. In objection of the above, Addis TV, South TV, Oromia TV, Tigray TV, ESAT, Nahoo TV and MoE most of the time didn't consumed by the audience. 
Table 10: Times, the Respondents Spent on Radio Outlet

3.2. How much time do you spend on the following media on a daily basis?

\begin{tabular}{|c|c|c|c|c|c|c|c|c|c|c|}
\hline \multirow[t]{2}{*}{ Radios } & \multicolumn{2}{|l|}{ None } & \multicolumn{2}{|c|}{ Less than $1 \mathrm{hr}$. } & \multicolumn{2}{|l|}{ 1-2hrs. } & \multicolumn{2}{|l|}{ 3-4 hrs. } & \multicolumn{2}{|c|}{$\begin{array}{l}5 \text { and above } \\
\text { hrs. }\end{array}$} \\
\hline & Frequency & $\%$ & Frequency & $\%$ & Frequency & $\%$ & Frequency & $\%$ & Frequency & $\%$ \\
\hline $\begin{array}{l}\text { Ethiopian } \\
\text { Radio }\end{array}$ & 338 & 40.9 & 280 & 33.9 & 146 & 17.7 & 40 & 4.8 & 23 & 2.8 \\
\hline $\begin{array}{l}\text { Amhara } \\
\text { Radio/FM }\end{array}$ & 221 & 26.7 & 296 & 35.8 & 211 & 25.5 & 83 & 10.0 & 16 & 1.9 \\
\hline Radio Fana & 441 & 53.3 & 227 & 27.4 & 120 & 14.5 & 44 & 5.3 & 25 & 3.0 \\
\hline VOA & 585 & 70.7 & 165 & 20.0 & 77 & 9.3 & 0 & 0.0 & 0 & 0.0 \\
\hline DW & 676 & 81.7 & 107 & 12.9 & 44 & 5.3 & 0 & 0.0 & 0 & 0.0 \\
\hline Wazema & 669 & 80.9 & 89 & 10.8 & 23 & 2.8 & 36 & 4.4 & 10 & 1.2 \\
\hline Abay & 667 & 80.7 & 118 & 14.3 & 25 & 3.0 & 10 & 1.2 & 11 & 1.3 \\
\hline Hibir & 664 & 80.3 & 98 & 11.9 & 53 & 6.4 & 12 & 1.5 & 0 & 0.0 \\
\hline
\end{tabular}

As stated above in table 10, the respondents were spent their own times on radio programs. $40.9 \%$ of the respondents didn't spent any time on Ethiopian Radio. 33.9\% of the respondents spent less than one hour, whereas $17.7 \%$ of the respondents spent $1-2$ hours on Ethiopian Radio. $4.8 \%$ and $2.8 \%$ of the respondents spent 3-4 and 5 and above hours above respectively. The respondents spent their time on Amhara radio/FM; $35.8 \%$ less than one hour, $25.5 \%$ of $1-2$ hours, $10 \%$ of $3-4$ hours, and $1.9 \%$ of them more than five hours, but $26.7 \%$ didn't spent and time on Amhara Radio Programs.

More than half percent (53.3\%) didn't use Radio Fana while 27.4\% of them spent less than one hour. $14.5 \%$ of the respondents' use Radio Fana 1-2 hours in a daily base, and 5.3\% of them sent 3-4 hours and the rest (3\%) 5 and more than five hours in a daily base.

The respondents were not invest much with the rest radios; VoA $(70.7 \%)$, DW $(81.7 \%)$, Wazema $(80.9 \%)$, Abay $(80.7 \%)$, and Hibir (80.3\%). As the data shows, the respondents spent less than one hour on the following radios; VOA $(20 \%)$, DW $(12.9 \%)$, Wazema $(10.8 \%)$, Abay $(14.3 \%)$ and Hibir $(11.9 \%)$. These media are international and online radios. Especially VOA and DW have one hour program in a day.

Most (33.3\%) of the respondents didn't spent any time on Radio Fana. 27.4\% of the respondents spent less than one hour. On the contrary, $14.5 \%$ of them spent $1-2$ hours in daily bases. The rest $(5.3 \%$ and $3 \%)$ of them spent more than three hours. The rest radios (VoA-70.7\%, DW-80.7\%, Wazema-80.9\%, Abay-80.7\%, and Hibir$80.3 \%$ ) hadn't any customers and they didn't listened by most of the audiences in a daily bases.

Table 11: Times, the Respondents Spent on Publication Outlet 3.3. How much time do you spend on the following media on a weekly basis?

\begin{tabular}{|c|c|c|c|c|c|c|c|c|c|c|}
\hline \multirow[t]{2}{*}{ Publications } & \multicolumn{2}{|l|}{ None } & \multicolumn{2}{|c|}{$\begin{array}{l}\text { One time }(10-20 \\
\text { min) }\end{array}$} & \multicolumn{2}{|c|}{$\begin{array}{l}\text { Twice } \quad(21-30 \\
\text { min) }\end{array}$} & \multicolumn{2}{|l|}{$\begin{array}{l}\text { Thrice(31- } \\
\text { 50min) }\end{array}$} & \multicolumn{2}{|c|}{$\begin{array}{l}\text { Weekend (1-2 } \\
\text { hrs.) }\end{array}$} \\
\hline & Frequency & $\%$ & Frequency & $\%$ & Frequency & $\%$ & Frequency & $\%$ & Frequency & $\%$ \\
\hline $\begin{array}{l}\text { Addis } \\
\text { Zemen }\end{array}$ & 407 & 49.2 & 276 & 33.4 & 101 & 12.2 & 32 & 3.9 & 11 & 1.3 \\
\hline $\begin{array}{l}\text { Addis } \\
\text { Admas }\end{array}$ & 543 & 65.7 & 188 & 22.7 & 70 & 8.5 & 19 & 2.3 & 7 & 0.8 \\
\hline Bekur & 608 & 73.5 & 140 & 16.9 & 53 & 6.4 & 22 & 2.7 & 4 & 0.5 \\
\hline Reporter & 492 & 59.5 & 165 & 20.0 & 123 & 14.9 & 29 & 3.5 & 18 & 2.2 \\
\hline
\end{tabular}

As shown above, the question was being asked to know the respondents newspaper choice and preferably in line with the time that they spent on it. According to the result, most of the respondents didn't choose and read Bekur Newspaper (73.5\%), Addis Admas newspaper (65.7\%), Reporter newspaper (59.5\%) and Addis Zemen newspaper (49.2\%). On the other hand, some people spent less than 20' of their time by reading Addis Zemen (33.4\%), Addis Admas (22.7\%), Reporter (20\%) and Bekur newspaper once in a week.

Others also read and spent 21-30' of their time on reading Bekur (14.9\%), Addis Zemen (12.2\%), Addis Admas (8.5\%) and Bekur (6.4\%) newspaper twice a week. In addition to this, the rest spent 31-50' in reading Addis Zemen (3.9\%), Reporter (3.5\%), Bekur (2.7\%) and Addis Admas (2.3\%) newspaper. Few of them were spent one and above hours in reading different newspapers in weekend. 
Table 12: Times, the Respondents Spent on Social Media Outlet

3.4. How much time do you spend on the following media on a daily basis?

\begin{tabular}{|l|l|l|l|l|l|l|l|l|l|l|l|}
\hline \multirow{2}{*}{ Social Media } & None & \multicolumn{2}{l|}{ Less than 1 hr. } & \multicolumn{2}{l|}{ 1-2hrs. } & \multicolumn{2}{l|}{ 5 hrs. } & \multicolumn{2}{l|}{ and above hrs. } \\
\cline { 2 - 13 } & Frequency & $\%$ & Frequency & $\%$ & Frequency & $\%$ & Frequency & $\%$ & \multicolumn{2}{l|}{ Frequency } & $\%$ \\
\hline Facebook & 235 & 28.4 & 196 & 23.7 & 121 & 14.63 & 100 & 12.1 & 84 & 10.2 \\
\hline Youtube & 554 & 67.0 & 157 & 19.0 & 78 & 9.43 & 20 & 2.4 & 18 & 2.2 \\
\hline Twitter & 651 & 78.7 & 133 & 16.1 & 24 & 2.90 & 13 & 1.6 & 6 & 0.7 \\
\hline Messenger & 480 & 58.0 & 206 & 24.9 & 97 & 11.73 & 20 & 2.4 & 24 & 2.9 \\
\hline Imo & 557 & 67.4 & 148 & 17.9 & 85 & 10.28 & 15 & 1.8 & 22 & 2.7 \\
\hline Telegram & 606 & 73.3 & 139 & 16.8 & 42 & 5.08 & 18 & 2.2 & 22 & 2.7 \\
\hline Viber & 610 & 73.8 & 143 & 17.3 & 38 & 4.59 & 13 & 1.6 & 23 & 2.8 \\
\hline Whats up & 637 & 77.0 & 107 & 12.9 & 66 & 7.98 & 10 & 1.2 & 7 & 0.8 \\
\hline Email & 573 & 69.3 & 144 & 17.4 & 50 & 6.05 & 40 & 4.8 & 20 & 2.4 \\
\hline
\end{tabular}

As indicated above table, the majority of the respondents were awarded about social media, but most of them they didn't spent any time on Twitter (78.7\%), Whats up (77\%), Viber (73.8\%), Telegram (73.3\%), Email (69.3\%), Imo (67.4\%), Youtube (67\%), Messenger (58\%) and Facebook (28.4\%).Except 23.7\% of the Facebook users, the others (i.e. less than 20\%) use these social media less than one hour. Few of them spent more than one hour on social media. When we compare the time that the respondents spent on social media, Facebook had a good chance in respondents' choice.

Table 13: Times, the Respondents Spent on player electronics devices

3.5. How much time do you spend on the following media on a daily basis?

\begin{tabular}{|l|l|l|l|l|l|l|l|l|l|l|l|}
\hline \multirow{2}{*}{ Player devices } & None & Frequency & $\%$ & Frequency & $\%$ & Frequency & $\%$ & Frequency & $\%$ & \multicolumn{2}{l|}{5 and above hrs. } \\
\hline & 395 & 47.8 & 178 & 21.5 & 150 & 18.1 & 83 & 10.0 & 21 & 2.5 \\
\hline $\begin{array}{l}\text { Watching } \\
\text { CDs/DVDs }\end{array}$ & 129 & 15.6 & 218 & 26.4 & 192 & 23.2 & 158 & 19.1 & 130 & 15.7 \\
\hline $\begin{array}{l}\text { Listening to } \\
\text { music/hymn } \\
\text { flash/memory }\end{array}$ & 579 & 70.0 & 100 & 12.1 & 50 & 6.0 & 70 & 8.5 & 28 & 3.4 \\
\hline $\begin{array}{l}\text { Playing } \\
\text { electronics } \\
\text { games }\end{array}$ & 5 & & & & & & & & & & \\
\hline
\end{tabular}

As shown in table 13, respondents were use different electronics tools to listen and/or watching music or different movies. $70 \%$ of the respondents didn't playing electronics games, $47.8 \%$ of the respondents didn't watching CDs/DVDs and $15.6 \%$ of them also didn't listening music/hymn with flash/memory. They were spent time in watching CDs/DVDs, less than one hour (21.5\%), 1-2 hours (18.1\%), 3-4 hours (10\%) and five and above hours $(2.5 \%)$. They also spent their time in listening to music/hymn with flash or memory (i.e. less than one hour (26.4\%), 1-2 hours (23.2\%), 3-4 hours (19.1\%), and five and above 15.7\%). On the other hand, few of the respondents were spent their time on playing electronics games.

As stated in table 9, 10,11, 12 and 13, the respondents spent different times the media outlets. There is a big gap inform of consumption between the satellite and analogues media messages. Audiences are relatively consumed TV and social media.

"We only watch selected media that suits for our feelings. Most of the media haven't good program schedule and haven't quality program. We like to listen, watch and read love stories and prominent person autography and biography." (FGDP 1 and 7)

The program schedules, the quality of the program, the attractiveness of the medium, the access of the media are determined the time spent on the media outlets. Besides of the personal characteristics, the media ownership, credibility, source of information were mentioned by the discussants. 
Table 14: How much do you like the following TV programs?

\begin{tabular}{|c|c|c|c|c|c|c|c|c|c|c|}
\hline \multirow[t]{2}{*}{$\begin{array}{l}\text { TV } \\
\text { Programs }\end{array}$} & \multicolumn{2}{|c|}{$\begin{array}{l}\text { Dislike very } \\
\text { much }\end{array}$} & \multicolumn{2}{|l|}{ Dislike } & \multicolumn{2}{|l|}{ None } & \multicolumn{2}{|l|}{ Like } & \multicolumn{2}{|c|}{ Like very much } \\
\hline & Frequency & $\%$ & Frequency & $\%$ & Frequency & $\%$ & Frequency & $\%$ & Frequency & $\%$ \\
\hline News & 182 & 22.0 & 46 & 5.6 & 34 & 4.1 & 394 & 47.6 & 171 & 20.7 \\
\hline Drama & 80 & 9.7 & 39 & 4.7 & 45 & 5.4 & 383 & 46.3 & 280 & 33.9 \\
\hline Music & 78 & 9.4 & 49 & 5.9 & 59 & 7.1 & 401 & 48.5 & 240 & 29.0 \\
\hline Discussion & 151 & 18.3 & 64 & 7.7 & 131 & 15.8 & 348 & 42.1 & 133 & 16.1 \\
\hline Sport & 144 & 17.4 & 42 & 5.1 & 98 & 11.9 & 321 & 38.8 & 222 & 26.8 \\
\hline Shows & 177 & 21.4 & 80 & 9.7 & 80 & 9.7 & 283 & 34.2 & 207 & 25.0 \\
\hline Politics & 201 & 24.3 & 81 & 9.8 & 148 & 17.9 & 271 & 32.8 & 126 & 15.2 \\
\hline Educational & 107 & 12.9 & 26 & 3.1 & 70 & 8.5 & 326 & 39.4 & 298 & 36.0 \\
\hline Movies & 113 & 13.7 & 66 & 8.0 & 37 & 4.5 & 302 & 36.5 & 309 & 37.4 \\
\hline
\end{tabular}

As the data shows, the respondents were asked questions about the TV programs how they like or dislike. The respondents were in favor of TV programs; news $(68.3 \%)$, dramas $(80.2 \%)$, music $(77.5 \%)$, discussion $(58.2 \%)$, sport $(65.6 \%)$, shows $(59.2 \%)$, politics $(48 \%)$, educational $(75.4 \%)$ and movies $(73.9 \%)$. This indicated that most of the respondents have (good) interests in TV programs. As they said, they hadn't much interest for politics and show programs. They also attached their reason with the current situation.

"We are excited to watch series movies, shows and current news." (FGDP 3)

The community are happy watching different media programs; however, as mentioned the program schedule will mater them.

Table 15: Among the following media which is the most important to you?

\begin{tabular}{|l|l|l|l|l|l|l|}
\hline \multirow{2}{*}{$\begin{array}{c}\text { Types of } \\
\text { media }\end{array}$} & Very important & Slightly important & \multicolumn{2}{l|}{ Not at all important" } \\
\cline { 2 - 7 } & Frequency & $\%$ & Frequency & $\%$ & Frequency & $\%$ \\
\hline Newspaper & 401 & 48.5 & 322 & 38.9 & 104 & 12.6 \\
\hline TV & 630 & 76.2 & 172 & 20.8 & 25 & 3.0 \\
\hline Radio & 543 & 65.7 & 323 & 39.1 & 52 & 6.3 \\
\hline Internet & 556 & 67.2 & 201 & 24.3 & 70 & 8.5 \\
\hline
\end{tabular}

As shown in table 15, respondents are ranked the importance of media according to their preferences. In their preferences choice, only the main stream media outlets were presented. $48.5 \%, 38.9$ and $12.6 \%$ of the respondents were ranked that newspaper as very important, slightly important and not at all important correspondingly.

The respondents graded that TV as very important $(76.2 \%)$, and slightly important $(76.2 \%)$; radio as very important $(65.7 \%)$, slightly important $(28.1 \%)$ and the rest said that it had not important with different media outlets. The rest of the respondents had an idea that TV and radio haven't any importance.

And also $62.2 \%$ of the respondents graded that internet is very important, and $24.3 \%$ of the respondents said that internet is slightly important. Few of them stated that it hasn't any importance at all.

Generally, most of the respondents believe and graded that media are very important for them. It is obvious that there have been considerable changes in media preferences, so the patterns of change have been different across various socio-demographic groups.

By looking at the basic factors that might influence media preferences among the respondent's, the researchers discover that age, education, gender, occupation of the respondents have a significant impact on the preferences patterns. Young respondents show less interest for newspapers when we compare aged groups. Young generations in the $21^{\text {st }} \mathrm{C}$ are highly dependent on online media. Respondents educational level playing a great role in media preferences. TV and radio have their own unique features which includes both literates and illiterate. 
Table 16: Which is/are the most important criterion/criteria when you choosing particular media as information source

\begin{tabular}{|l|l|l|}
\hline Criterion/criteria & Frequency & Percent \\
\hline Impartiality and credibility & 270 & 32.6 \\
\hline Timely/ current information & 492 & 59.5 \\
\hline Independence from political interests & 203 & 24.5 \\
\hline Independence from economic interests & 83 & 10.0 \\
\hline Accessibility & 185 & 22.4 \\
\hline In-depth reporting on selected topics & 174 & 21.0 \\
\hline Preferably & 169 & 20.4 \\
\hline Price or access fee & 67 & 8.1 \\
\hline Quality and originality of individual authors (journalists, commentators etc.) & 126 & 15.2 \\
\hline Similarity of particular outlet's political viewpoints to my viewpoints & 29 & 3.5 \\
\hline I do not know & 10 & 1.2 \\
\hline
\end{tabular}

As stated above, the participants have their own criteria to choose a particular media as an information sources, though $27 \%$ of the respondents timely/current information, $15 \%$ of them impartiality and credibility, $11 \%$ of them also said independence from political interest, $10 \%$ accessibility, $10 \%, 9 \%, 7 \%, 5 \%, 4 \%$, and $2 \%$ as in-depth reporting on selected topics, preferably, quality and originality of individual authors, price/access free and similarity of particular outlet's political viewpoints to my viewpoints are their criteria correspondently.

Media choices reflect the needs and preferences of consumers and that the consumers actively shape their own media environment. People normally consume different types of media indistinctly. Whatever it is, they select the media messages based on stated criteria.

In Debre Tabor community context, accessible, fresh, credible, and smart information were the most important criteria to choose a particular media. The purposively seeking of information is a consequence of a need to satisfy some goal. The people seeking information with manual information systems or with computer based systems. Set the criteria to select the sources of information is important. The community has set values which help them to get accurate information, to select media information.

Table 17: To what extent do you agree with the statements below?

\begin{tabular}{|c|c|c|c|c|c|c|c|c|c|c|c|}
\hline \multirow[t]{2}{*}{ S.N } & \multirow[t]{2}{*}{ Statement } & \multicolumn{2}{|c|}{ I do not agree at all } & \multicolumn{2}{|c|}{ I do not agree } & \multicolumn{2}{|c|}{$\begin{array}{l}\text { I neither agree nor } \\
\text { disagree }\end{array}$} & \multirow{2}{*}{$\frac{\text { I agree }}{\text { Frequency }}$} & \multicolumn{3}{|c|}{ I fully agree } \\
\hline & & Frequency & $\%$ & Frequency & $\%$ & Frequency & $\%$ & & $\%$ & Frequency & $\%$ \\
\hline 1. & $\begin{array}{lc}\text { Media perfect } & \text { the } \\
\text { interest of the } \\
\text { community in a country }\end{array}$ & 207 & 25.0 & 177 & 21.4 & 98 & 11.9 & 251 & 30.4 & 94 & 11.4 \\
\hline 2. & $\begin{array}{l}\text { Media reveal things that } \\
\text { are wrong within } \\
\text { community }\end{array}$ & 120 & 14.5 & 146 & 17.7 & 107 & 12.9 & 323 & 39.1 & 131 & 15.8 \\
\hline 3. & $\begin{array}{l}\text { Media are source of } \\
\text { agenda }\end{array}$ & 75 & 9.1 & 51 & 6.2 & 105 & 12.7 & 427 & 51.6 & 169 & 20.4 \\
\hline 4. & $\begin{array}{l}\text { Media are a means of } \\
\text { promoting economic } \\
\text { interests }\end{array}$ & 84 & 10.2 & 77 & 9.3 & 134 & 16.2 & 398 & 48.1 & 134 & 16.2 \\
\hline 5. & Media as a civic forum & 98 & 11.9 & 86 & 10.4 & 86 & 10.4 & 370 & 44.7 & 187 & 22.6 \\
\hline 6. & $\begin{array}{l}\text { Media are a means of } \\
\text { promoting political } \\
\text { interests }\end{array}$ & 148 & 17.9 & 128 & 15.5 & 118 & 14.3 & 311 & 37.6 & 122 & 14.8 \\
\hline 7. & $\begin{array}{l}\text { Media help people } \\
\text { become better informed } \\
\text { and educated }\end{array}$ & 95 & 11.5 & 58 & 7.0 & 87 & 10.5 & 409 & 49.5 & 178 & 21.5 \\
\hline 8. & $\begin{array}{l}\text { Media stimulate } \\
\text { consumerism }\end{array}$ & 116 & 14.0 & 104 & 12.6 & 138 & 16.7 & 349 & 42.2 & 120 & 14.5 \\
\hline 9. & $\begin{array}{l}\text { media contribute to the } \\
\text { increase of intolerance } \\
\text { in community }\end{array}$ & 191 & 23.1 & 157 & 19.0 & 148 & 17.9 & 233 & 28.2 & 98 & 11.9 \\
\hline 10. & $\begin{array}{l}\text { Media as mobilizing } \\
\text { agent }\end{array}$ & 137 & 16.6 & 175 & 21.2 & 129 & 15.6 & 280 & 33.9 & 106 & 12.8 \\
\hline 11. & $\begin{array}{l}\text { Media contribute to the } \\
\text { increase of violence in } \\
\text { community }\end{array}$ & 147 & 17.8 & 106 & 12.8 & 98 & 11.9 & 299 & 36.2 & 177 & 21.4 \\
\hline 12. & $\begin{array}{l}\text { Media enhance } \\
\text { knowledge and } \\
\text { understanding of the } \\
\text { needs and interests of } \\
\text { various social groups } \\
\text { and communities }\end{array}$ & 120 & 14.5 & 103 & 12.5 & 74 & 8.9 & 314 & 38.0 & 216 & 26.1 \\
\hline
\end{tabular}

According to the data, $46.4 \%$ of the people were disagreed that media perfect the interest of the community in a country, but $41.8 \%$ of them also agreed. And also, $54.9 \%$ of the people said that media reveal things that are wrong within community. On the other hand $32.2 \%$ of the respondents don't believe it. $72 \%$ of the respondents agreed that media are source of agenda, and $15.3 \%$ of the respondents don't agree on it.

$74.3 \%$ of the respondents' agreed that media are a means of promoting economic interests of the community and $19.5 \%$ of the respondents also don't agreed. And also, $77.3 \%$ of the respondents agreed that 
media serves as a civic forum, but $22.3 \%$ of the respondents refused it. Although $52.4 \%$ of the respondents stated that media are a means of promoting political interests, and the others $(33.4 \%)$ don't agreed on it. While, $71 \%$ of the respondent agreed that media help people become better informed and educated; however, $18.5 \%$ didn't agree on this. $56.7 \%$ of the respondents agreed that media stimulate consumerism, but $26.6 \%$ of the people don't agree. While $42.1 \%$ of the respondent don't agreed that media contribute to the increase of intolerance in community, but $40.1 \%$ of the respondents aged on it. And similarly $46.7 \%$ of the respondents don't agreed that the respondents believe that media as mobilizing agent; the rest of the respondents $(37.8 \%)$ are agreed.

As the data shows, $57.6 \%$ of the respondents agreed that media contribute to the increase of violence in community, but $30.6 \%$ they didn't agree with this idea. And also $64.1 \%$ of the respondents believe that media enhance knowledge about and understanding of the needs and interests of various social groups and communities. $27 \%$ of them also disagree with this idea.

In the community, media are a means of promoting economic interests $(74.3 \%)$ in forms of stimulate consumerism $(56.7 \%)$, political interests $(52.4 \%)$ in forms of set agenda $(72 \%)$ and serve as a civic forum $(77.3 \%)$ as agent of change $(46.7 \%)$ of the community. Media enhance knowledge and understanding of the needs and interests of various social groups and communities (64.1\%) and it help them become better informed and educated $(71 \%)$ about the world. Media contribute to the increase of violence $(57.6 \%)$, and decrease intolerance $(42.1 \%)$ in community. Even if the media reveal things that are wrong with in a community $(54.9 \%)$, they are not perfect (46.4\%) to the interests of the community in a country.

"We agreed that media have the power to change the attitudes of the community. The news, promotions, programs and information are an agenda that influences our day-to-day life. The media framed the public perceptions depend on the interests of the rulers; this influences our culture and norms." (FGDP 4, 6. 10)

As the discussant stated above most of the people have a good awareness on the media usage, functions, and principles.

Table 18: Which types of things influenced your perception on the media choice?

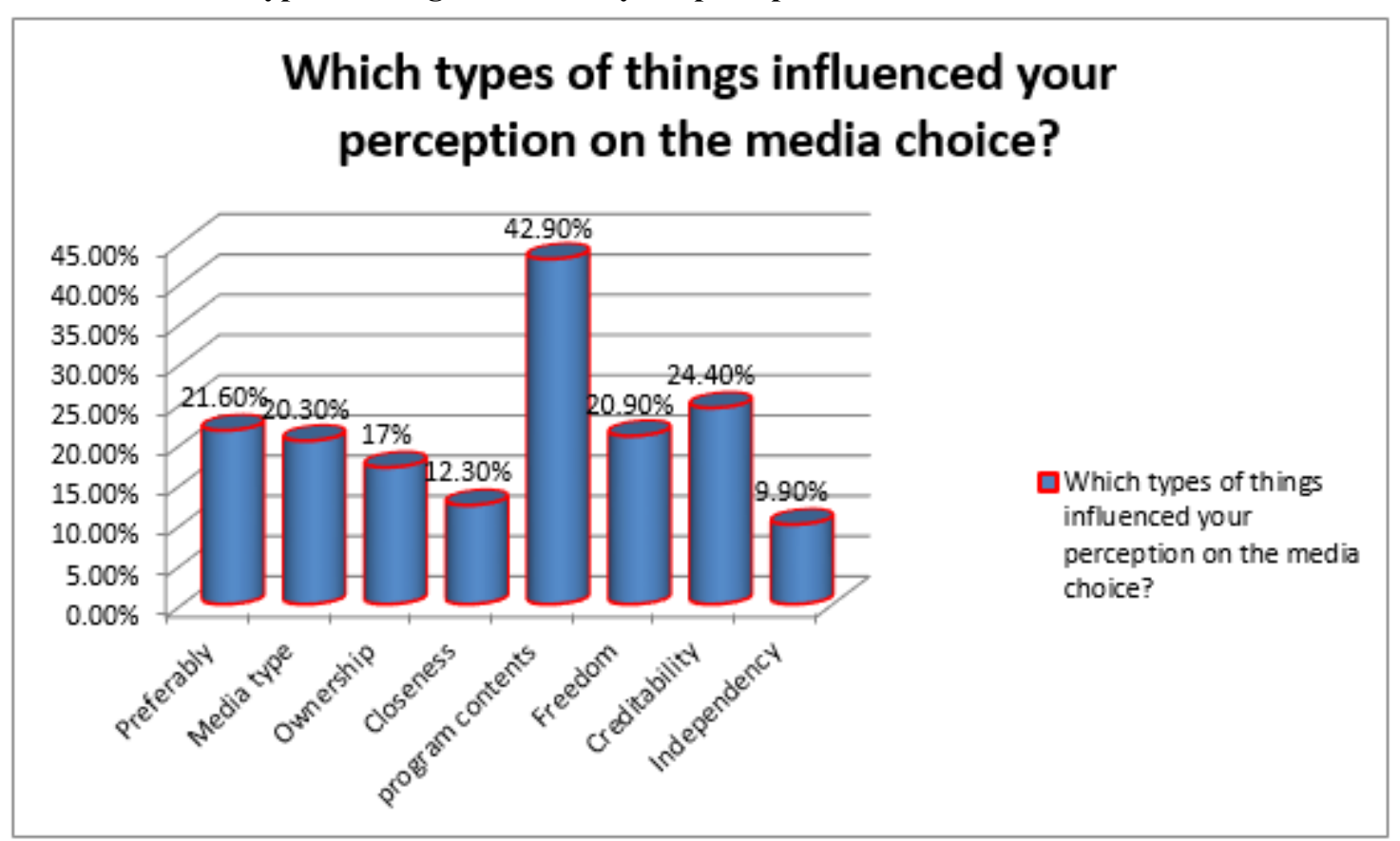

As shown above, participants are influenced their perception on their media choice. Among these, program contents $(42.9 \%)$, credibility $(24.4 \%)$, preferably $(21.6 \%)$, freedom $(20.9 \%)$, media type $(20.3 \%)$, ownership $(17 \%)$, closeness $(12.3 \%)$, and independency (9.9\%) are their prerequisite to choose the media type.

Media perceptions has its own cause and consequences; trust, hostility and influences. These media impact are not only empirically connected. Media have become central to our politics, economy and social systems. Thus, Debre Taboe Community were choose the particular media by the following criteria; program contents $(42.9 \%)$, credibility $(24.4 \%)$, preferably $(21.6 \%)$ media type $(20.3 \%)$ and freedom of media were the most that has an impact on the community's media choice. As they sated that the government influence, the economy pressure, media ownership and control had a major influences on their media choice. 
Table 19: which media genres that consumed frequently

Which media genres do you consume most frequently?

\begin{tabular}{|l|l|l|}
\hline & Frequency & Percent \\
\hline News & 386 & 46.7 \\
\hline Serials and/or series & 128 & 15.5 \\
\hline Films & 440 & 53.2 \\
\hline Sport & 284 & 34.3 \\
\hline Cultural and/or arts programs & 14 & 1.7 \\
\hline Telenovelas & 143 & 17.3 \\
\hline Entertainment shows & 294 & 35.6 \\
\hline Weather & 216 & 26.1 \\
\hline Documentaries & 58 & 7.0 \\
\hline Reality shows & 70 & 8.5 \\
\hline Talk shows & 247 & 29.9 \\
\hline None of these & 267 & 32.3 \\
\hline
\end{tabular}

In line with the above information, the respondents regularly consume different media information. Then the researchers tried to put based on their hierarchy. These are, films $(53.2 \%)$, news $(46.7 \%)$, entertainment shows $(35.6 \%)$, sport $(34.3 \%)$, talk shows $(29.9 \%)$, weather(26.1\%), telenovelas $(17.3 \%)$, serials and/or series $(15.5 \%)$, reality shows $(8.5 \%)$, documentaries $(7 \%)$ and cultural and/or arts programs.

“...entertainment programs are our best choice. We regularly listen 2 O'clock news and find other programs that enlighten us.” (FGDP 4)

The respondents choices determine based on their media schedule and transmission. Media consumption focused on personality characteristics can easily impress people. All types of media provide relatively easy access to information and entertainment. Debre Tabor Community is dependent in need of information and entertainment.

Table 20: types of information those were preferable to the respondents

Which type(s) of information is/are preferable to you?

\begin{tabular}{|l|l|l|}
\hline & Frequency & Percent \\
\hline Political & 190 & 23 \\
\hline Social & 229 & 28 \\
\hline Business & 149 & 18 \\
\hline Agriculture & 119 & 14 \\
\hline Sport & 305 & 37 \\
\hline Health & 263 & 32 \\
\hline Entertainments & 366 & 44 \\
\hline
\end{tabular}

According to the data collected at the end of the survey, the respondents were preferable for entertainment $(44 \%)$, sport $(37 \%)$, health $(32 \%)$, social $(28 \%)$, political $(23 \%)$, business $(18 \%)$ and agriculture $(14 \%)$ information.

"Entrainment information are best to consume. It will be sport, movies, and shows. This information has the power to catch the attentions of the audience." (FGDP \&)

As they stated, old media provided information and entertainment in the pre-set schedule, leaving people with more limited options. In addition to this, they use TV for leisure-time consumption in household and in hotel level. 
Table 21: the media contents that the respondents give most of their attention

For which media content or topic do you give most of your attention?

\begin{tabular}{|l|l|l|}
\hline & Frequency & Percent \\
\hline Domestic politics & 222 & 26.8 \\
\hline Local News & 187 & 22.6 \\
\hline Economy/finance/stock exchange & 107 & 12.9 \\
\hline Foreign politics & 143 & 17.3 \\
\hline Culture/arts & 222 & 26.8 \\
\hline Celebrity topics & 104 & 12.6 \\
\hline Social issues & 279 & 33.7 \\
\hline Science/technology & 286 & 34.6 \\
\hline Environment/ecology & 136 & 16.4 \\
\hline Lifestyle & 290 & 35.1 \\
\hline Sport & 248 & 30.0 \\
\hline Crime & 132 & 16.0 \\
\hline Health Advice & 240 & 29.0 \\
\hline None of these & 31 & 3.7 \\
\hline
\end{tabular}

As shown above, the respondents give different attentions for media contents which transmitted. Though, lifestyle (35.1\%), science/technology (34.6\%), social issues (33.7\%), sport (30\%), health advice (29\%), domestic politics $(26.8 \%)$, culture/arts $(26.8 \%)$, local news $(22.6 \%)$, foreign politics $(17.3 \%)$, environmental/ecology $(16.4 \%)$, crime (16\%), finance/stock exchange (12.9\%) and celebrity topics $(12.6 \%)$.

"We are conscious to know the prominent person profiles and science and technology innovation. Besides to this, we give high priority for the domestic and socio-cultural information." (FGDP 3, 9 and 10)

The city is aged that is above 700 years old. The community also has toasty relation each other in their social life. They have almost similar attitude and perception to everything.

Table 22: Do you want the establishment of community radio in Debre Tabor Town?

\begin{tabular}{|l|l|l|l|l|}
\hline & Frequency & Percent & Valid Percent & Cumulative Percent \\
\hline Yes, I want & 691 & 83.6 & 83.6 & 83.6 \\
No, I don't want & 136 & 16.4 & 16.4 & 100.0 \\
Total & 827 & 100.0 & 100.0 & \\
\hline
\end{tabular}

As shown above, $83.6 \%$ of the respondents have an interest to established community radio in Debre Tabor Town. The rests haven't any interest that community radio establishes in Debre Tabor Town.

At the ends of the questioner, we tried to put the above question to know the interests of the community to establish a community radio. Almost all of the community have an interest to establish their own community radio that runs by the community. The discussants also state that they need media that serves as voice for them.

\section{Conclusions}

Media play a prominent role for the development of one country. Media are tools to change the attitudes and develop good images of the people on any activities. Change starts with perceptions that lead to real path of preferences. Social perception make sense of social world, this is related to phenomenon that how we make impressions of and make inferences about other people. The messages that are consumed by the people constructs the social identify. Studding the communities' media perceptions and preferences are important to use appropriate media and prepared fitted messages to them.

In this study, the data obtained through questionnaires and focus group discussion within six kebeles of Debre Tabor Town. 947 people were involved in this study. The participants are heterogeneous in educational level, age, sex, religion and the place they lived. The participants believed that media are very significant tools to update their knowledge, skills and attitudes. They were used TV, internet and radio regularly as a real source of information. Media enhance knowledge and understanding of the needs and interests of various social groups and communities and it help them become well informed and educated about the world.

In the community, media are a means of promoting economic interests in forms of stimulate consumerism, political interests in forms of set agenda and serve as a civic forum as agent of change of the community. They stated that the media also set public and government agenda in forms of different program formats, entertainment, news, shows etc. Most of them spent one-two hours daily on media products especially on broadcast and social media; however, the time they spent on the media outlet determine based on the program schedule, credibility of the message and attractiveness. Not only are these, freshness of the information, impartiality of the message, and 
credibility, accessibility and program preparation styles are other criteria to consume the messages.

The community was complaining that media in their locality contribute to the increase violence and decrease intolerance in community. Even if the media reveal things that are wrong with in a community they are not perfect to the interests of the community that match the community cultures, norms, traditions and ethics. Lack of freedom, credibility, preferably, media ownership and control and accessibility are the determinate factors that affect the community media perceptions and preference.

\section{Acknowledgement}

We would like to thank in heart our respondents, Debre Tabor City Administration community and the people that contribute for the accomplishment of this work i.e. Hailu Minale, Director of Guna Tana Integrated Field Research Centerand Department heads.

\section{Researchers Address}

1. Destaw Bayable Yemer,

Researcher and lecturer, Guna-Tana Integrated Field Research and Development Center, Debre Tabor University

2. Dessalegn Yeshambel Wassie,

Lecturer and PhD canididate, Department of Journalism and Communication, Debre Markos University

\section{References}

Chan. Alex. (2007). Guiding Public Opinion through Social Agenda Setting: China's Media Policies, Journal of Contemporary China, Volume 16, Issue 53, Page 548.

Dominick, J.R. (2009). The dynamics of mass communication: Media in the digital age, 10th edition. New York: McGraw-Hill.

Katz, E., Blumler, J. G., \& Gurevitch, M. (1973). Uses and Gratifcations research. Public Opinion Quarterly, 37(4), 509-523. doi:10.1086/268109

Severin J, Werner. Tankard, Jr. W, James. (2001). Communication theories: origins, methods and uses in mass media, 5th edition, Longman.

Stahl, Bernd \& Tremblay, Monica \& Lerouge, Cynthia (2011), Focus groups and critical social IS research: how the choice of method can promote emancipation of respondents and researchers. EJIS. 20. 378-394

Turner. Lynn H, West. Richard, (2007), Introducing Communication Theory; Analysis and Application, Third Edition, McGraw Hill

Vallone, R.P., Ross, L., \& Lepper, M.R. (1985), The hostile media phenomenon: Biased perception and perceptions of media bias in coverage of the Beirut massacre. Journal of Personality and Social Psychology, 49, 577-588.

Wright, C. R. (1974). Functional analysis and mass communication revisited. In J. G. Blumler \& E. Katz (Eds.), The uses of mass communications (pp. 197-212). Beverly Hills: SAGE Publications, Inc. Retrieved from http://repository.upenn.edu/asc_papers/8

\section{Webs}

http://cmm306.wikifoundry.com/page/Uses+and+Gratification\%3A+Blumler+and+Katz http://dh.howard.edu/newdirections/vol5/iss3/5

http://ffmgu.ru/images/c/c6/MASS_MEDIA.pdf

http://www.gamji.com/article6000/NEWS7617.htm

https://onlinelibrary.wiley.com/doi/pdf/10.1002/9781444361506.wbiems995

https://opentextbc.ca/researchmethods/chapter/reliability-and-validity-of-measurement/

https://pdfs.semanticscholar.org/f726/59af59d346ae461951ab1ef4307588e746ad.pdf

https://researchrundowns.com/mixed/mixed-methods-research-designs/

https://www.academia.edu/29086041/Public_Perception_of_Media_Role

https://www.ijhssnet.com/journals/Vol._1_No._5;_May_2011/25.pdf

https://www.researchgate.net/publication/259090925_Public_Perception_of_Media_Role

https://www.sophia.org/tutorials/media-in-the-21st-century

https://www.sophia.org/tutorials/media-in-the-21st-century

https://www.uq.edu.au/ccsc/mass-media-and-national-development-the-role-of-information-in-the-developing-

countries

https://courses.lumenlearning.com/suny-introductiontocommunication/chapter/functions-of-mass-

communication/ 